\title{
The Effects of Diurnal Intermittent Fasting On Proinflammatory Cytokine, Oxidative Stress and Heat Shock Protein 70 Levels
}

\author{
Yasar Tastemur (Corresponding author) \\ Department of Anatomy, School of Medicine, \\ Sivas Cumhuriyet University, Sivas, Turkey \\ E-mail: dryasar58@hotmail.com \\ Mustafa Ergul \\ Department of Biochemistry, Faculty of Pharmacy, \\ Sivas Cumhuriyet University, Sivas, Turkey \\ E-mail: m.ergul@yahoo.com.tr \\ Ahmet Sevki Taskiran \\ Department of Physiology, School of Medicine, \\ Sivas Cumhuriyet University, Sivas, Turkey \\ E-mail: ahmettaskiran@cumhuriyet.edu.tr \\ Ahmet Altun \\ Department of Pharmacology, School of Medicine, \\ Sivas Cumhuriyet University, Sivas, Turkey \\ E-mail: md.ahmetaltun@gmail.com \\ Hilmi Ataseven \\ Department of Gastroenterology, School of Medicine, \\ Sivas Cumhuriyet University, Sivas, Turkey \\ E-mail: hataseven@cumhuriyet.edu.tr
}

\begin{abstract}
Aim: In this study, it is aimed to assess the effect of intermittent diurnal fasting (DIF) at the beginning (2nd day of Ramadan fasting) and the end of the Ramadan (28th day of Ramadan fasting) on plasma levels of proinflammatory cytokines [tumor necrosis factor-alpha (TNF- $\alpha$ ) and interleukin 8 (IL-8)], heat shock protein 70 (Hsp70) and oxidative stress markers [total oxidant status (TOS) and total antioxidant status (TAS)].

Methods: Fifty healthy male volunteers aged between 25-45 years were included in the study. All subjects followed the same dietary regimen before and during Ramadan and were encouraged to continue their usual lifestyle and activities. All biochemical tests were made both at the beginning (2nd day of fasting) and the end of the Ramadan (28th day of fasting). Plasma levels of cytokines (TNF- $\alpha$ and IL-8) Hsp70 were assessed using enzyme-linked immunoassays (ELISA), and oxidative markers (TAS and TOS) were measured spectrophotometric methods.

Results: There was a significant decrease in the levels of TNF- $\alpha$, compared to the beginning of fasting $(p<0.05)$. However, there was no significant change in IL-8 levels between before and end of fasting ( $>0.05)$. Therefore, there was a significant increase in the Hsp70 levels compared to the beginning of fasting $(p<0.05)$. On the other hand, TOS levels reduced at the end of fasting compared to the beginning $(p<0.05)$. In addition, TAS levels were similar and looked unchanged during the period of fasting $(\mathrm{p}>0.05)$.

Conclusion: DIF decreased proinflammatory cytokine level and oxidative stress parameter while
\end{abstract} increasing the levels of Hsp70.

Keywords: Diurnal Intermittent Fasting, Ramadan, Proinflammatory Cytokines, Heat Shock Protein 70, Oxidative Stress 


\section{Special Issue of Health Sciences}

DOI: $10.7176 / J S T R / 6-03-41$

\section{Introduction}

Diurnal intermittent fasting (DIF) is practiced by hundreds of millions of Muslims during the month of Ramadan (Almeneessier \& Bahammam, 2018). The effects of DIF on human health have attracted the attention of investigators in the past few years. DIF is not similar to caloric restriction (CR), in which caloric intake is reduced for long periods, but meal frequency is preserved (Almeneessier \& Bahammam, 2018). During Ramadan DIF, fast performers abstain from food, drinks, and smoking from dawn to sunset for a period of one month. DIF during Ramadan fasting can be looked at as a time-restricted feeding (between dawn and sunset) protocol with no calorie restriction. Traditionally, 2 main meals are taken at night during Ramadan; the first after sunset and the second before dawn (Mindikoglu et al., 2017).

Cytokines are small glycoproteins produced by several cell types, especially white blood cells, which regulate immunity and response to inflammation. Their persistent elevation has negative effects on various organs and bodily functions, such as increasing the risk of diabetes, metabolic syndrome, and cardiovascular diseases (Yu et al., 2012). Studies in animal models have shown that low-calorie intake reduces the levels of proinflammatory cytokines (González et al., 2012). A few studies have examined inflammatory biomarkers during Ramadan DIF. A recent meta-analysis of 10 studies conducted on DIF performers during Ramadan demonstrated a small reduction in inflammatory biomarkers during fasting (Faris et al., 2019).

Oxidative stress is a phenomenon wherein there is an imbalance between the rate of oxidant formation and its elimination from the body (Birben et al., 2012). It has been known to be a promoting factor of various acute and chronic diseases, some of which are lethal (Sinha \& Dabla, 2015). Oxidative stress usually occurs when the generation of oxidants, as a byproduct of the metabolic processes is much higher than usual. However, several exogenous sources such as pollution and alcohol have been known to be major factors in oxidative stress (Birben et al., 2012).

The 70-kDa heat shock protein (Hsp70) family of molecular chaperones represents one of the most ubiquitous classes of chaperones and is highly conserved in all organisms. Members of the Hsp70 family control all aspects of cellular proteostasis such as nascent protein chain folding, protein import into organelles, recovering of proteins from aggregation, and assembly of multi-protein complexes (Shankar $\&$ Mehendale, 2014). These chaperones augment organismal survival and longevity in the face of proteotoxic stress by enhancing cell viability and facilitating protein damage repair. Extracellular Hsp70s have a number of cytoprotective and immunomodulatory functions (Daugaard et al., 2007). Hsp70s protect cells from the proteotoxic stress associated with abnormally rapid proliferation, suppress cellular senescence, and confer resistance to stress-induced apoptosis including protection against cytostatic drugs and radiation therapy (Murphy, 2013).

In the light of these data, we aimed to investigate the biological effects of intermittent fasting in the scope of inflammation, oxidative stress and protein folding.

\section{Materials and Methods}

\subsection{Study Design}

The study is conducted at Sivas Cumhuriyet University Medical Faculty Hospital under the revision and approval of Sivas Cumhuriyet University Ethical Committee during the 30 days of Ramadan in 2019. Fifty healthy male volunteers aged between 25-45 years were included in the study. All subjects followed the same dietary regimen before and during Ramadan and were encouraged to continue their usual lifestyle and activities. The volunteers are recruited from the hospital staff who is going to do fasting during the Ramadan to facilitate the follow-ups and volunteer accommodation. All biochemical tests were performed both at the beginning (2nd day of the Ramadan fasting) and the end of the Ramadan (28th day of the Ramadan fasting).

\subsubsection{Inclusion Criteria}

Healthy male volunteers between age 25 and 45 who are going to do fasting during the Ramadan.

\subsubsection{Exclusion Criteria}

People who have known chronic illness including hypertension, diabetes, cancer, and autoimmune 
diseases, people who are using medication for a chronic illness or planning to use medication during the Ramadan period and people who tend to have a peptic complaint which usually causes proton pump inhibitor (PPI) use during the Ramadan were excluded from the study.

2.2 Measurement of tumor necrosis factor-alpha (TNF- $\alpha)$, interleukin-6 (IL-6), interleukin-8 (IL-8) and heat shock protein 70 (Hsp70)

Enzyme-linked immunosorbent assay (ELISA) kits were used to measure the plasma concentrations of TNF- $\alpha$, IL-8 and Hsp70 (Enzo Life Science, New York., USA). The operation protocols were according to the manufacturer's instructions. There were standard curves used to calculate for all these kits. The coefficients of variation within and between plates were less than $10 \%$.

\subsection{Measurement of total antioxidant status (TAS) and total oxidant status (TOS)}

Plasma TAS levels were measured with an automated assay method developed by Erel (O Erel, 2003). Free radical reactions were started with the production of hydroxyl radicals by Fenton reaction, and the rate of the reaction was monitored by following the absorbance of colored dianisidyl radicals. Antioxidants in the sample suppressed the color formation to the degree that is proportional to their concentrations (O Erel, 2003). The results were stated in term of micro molar Trolox equivalent per milligram tissue protein ( $\mu \mathrm{mol}$ Trolox Eq/mg protein).

Plasma TOS levels concentrations were also measured with an automated assay method developed by Erel (Ozcan Erel, 2005). The method is based on the principle of the oxidation of ferrous ion to ferric ion in the presence of various oxidants in the sample and the measurement of the ferric ion by xylenol orange. The assay was calibrated with hydrogen peroxide (Ozcan Erel, 2005). The results were stated in terms of micro molar hydrogen peroxide equivalent per milligram tissue protein ( $\mu \mathrm{mol} \mathrm{H} 2 \mathrm{O} 2 \mathrm{Eq} / \mathrm{mg}$ protein).

\subsection{Statistical Analyses}

In this study, when alpha 0.05 beta $0.101-b=0.90$ was taken, it was decided to include 50 individuals and the power of the test was 0.90527 . When the data obtained from our study are loaded into SPSS 22.0 program, when the parametric test assumptions are fulfilled in the evaluation of the data, Cosmograph Smirnoff (Significance test of pairs difference), Wilcoxon test when the parametric test assumptions cannot be fulfilled, the correlation analysis will be applied to determine the relationships between variables.

\section{Results}

3.1. The effects of DIF on plasma TNF- $\alpha, I L-6, I L-8$ and Hsp70 levels

Levels of plasma TNF- $\alpha$ reduced after fasting compared to the beginning of fasting (Figure $1 ; \mathrm{p}<0.001$ ).

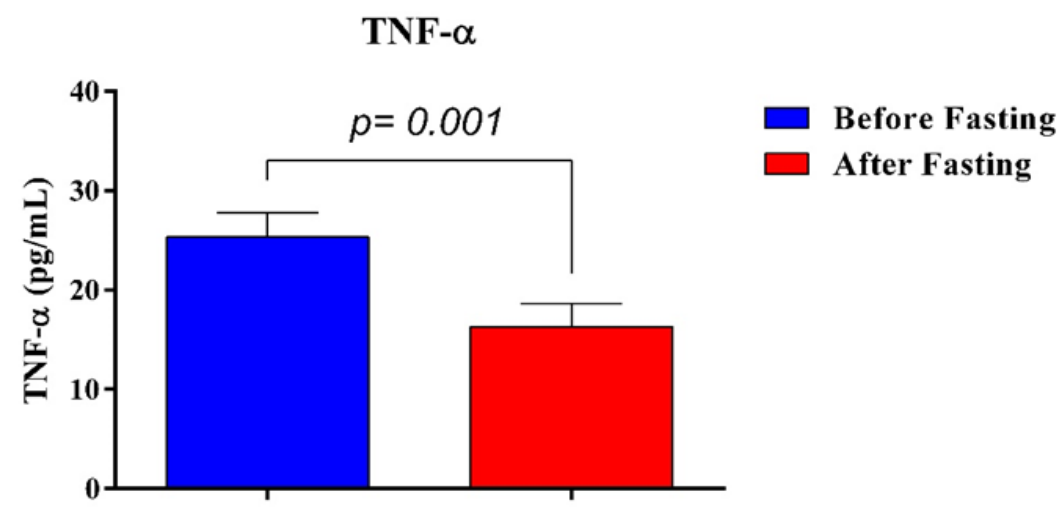

Figure 1. The effect of DIF on plasma TNF- $\alpha$ levels. Values are presented as mean \pm SEM

In addition, plasma IL-6 decreased after fasting compared to the beginning of fasting (Figure $2 ; \mathrm{p}<0.001$ ). 


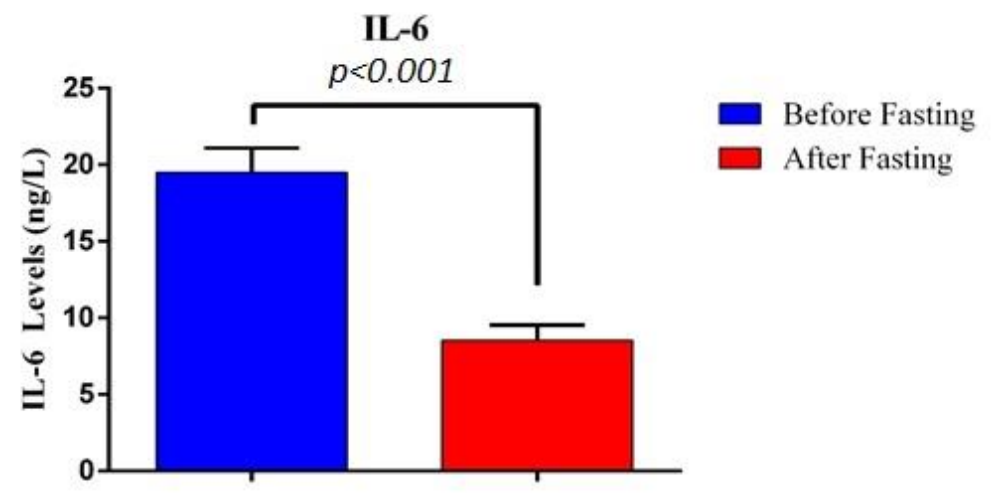

Figure 2. The effect of DIF on plasma IL-6 levels. Values are presented as mean $\pm \mathrm{SEM}$

On the other hand, there was no significance in plasma IL- 8 levels between before and after fasting (Figure 3; $>0.05$ )

\section{IL-8}

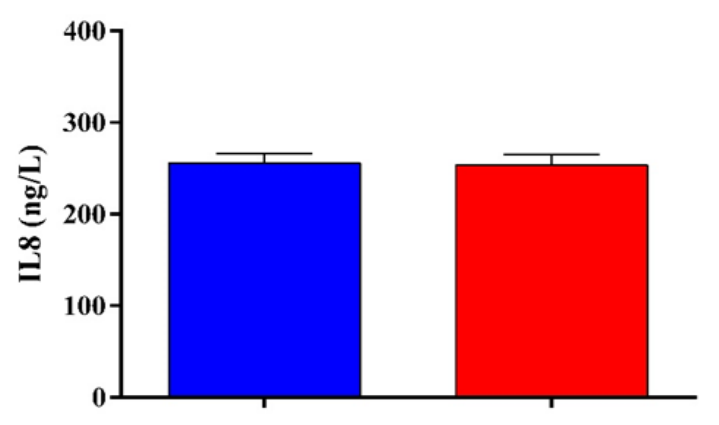




\subsection{The effects of DIF on plasma TAS and TOS levels}

There was no significance in plasma TAS levels between before and after fasting (Figure 5; $\mathrm{p}>0.05$ ).

\section{TAS}

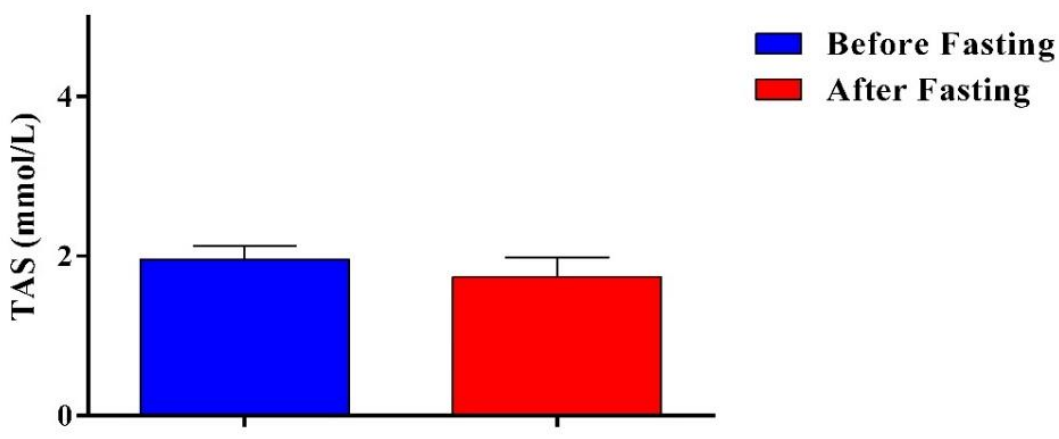

Figure 5. The effect of DIF on plasma TAS levels. Values are presented as mean \pm SEM

Therefore, levels of plasma TOS decreased after fasting compared to beginning of fasting (Figure 6; $\mathrm{p}<0.001)$.

\section{TOS}

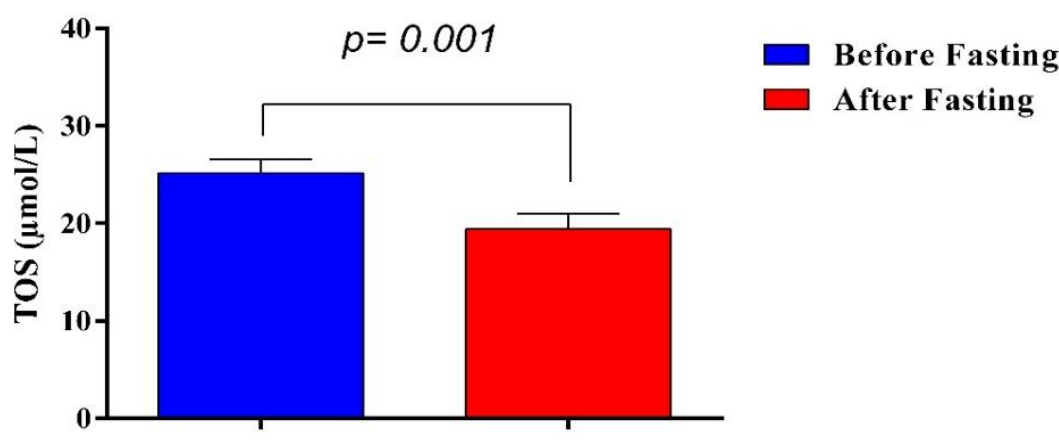

Figure 6. The effect of DIF on plasma TOS levels. Values are presented as mean \pm SEM

\section{Discussion and conclusion}

Fasting was a treatment method which is consistently practiced since the time of Hippocrates and was then developed in the United States at the beginning of the twentieth century by the few physicians. Their method of fasting consisted of water and tea, supported by enemas and physical exercise (Gilmore, 2001). In fact, the fasting concept goes way back, and all major religions have some kind of fasting including Islam. While religious fasts have partaken primarily for spiritual purposes, they also have the potential to affect one's physical health greatly. Accordingly, the health effects of religious fasting have recently been the subject of scientific inquiry, with most of the research being performed in the last two decades. Every year, a huge number of Muslims abstain from eating or drinking from dawn (Sahur) to nightfall (Iftar) during the sacred month of Ramadan, which keeps going between 28 also, 30 days. Along these lines, Ramadan fasting is like alternate day fasting (ADF), since the two fasts fuse feast periods and quick periods. The dining experience periods and quick times of Ramadan fasting are every 12 hours long on normal (Aksungar et al., 2005), which adds up to half of the 24-hour length for both the dining experience periods and quick times of ADF. Another significant contrast between the two types of fasting is that liquid admission is prohibited during the quick times of

Ramadan, while it is allowed consistently under an ADF convention. The regular dietary act of Ramadan fasting is to expend one huge dinner after dusk and one lighter supper before sunrise (Ibrahim et al., 2009), yet a few Muslims expend an extra supper before dozing (Roky et al., 2001). Muslims devour a more noteworthy assortment of nourishments during Ramadan looked at with the remainder of the year (Hallak \& Nomani, 1988). Likewise, sugary nourishments and drinks are expended all the more as often as possible during Ramadan (Fedail et al., 1982). 
The present study is conducted in Ramadan in Turkey, and the biological effect of intermittent fasting of Ramadan was investigated in terms of inflammatory cytokines, oxidative stress markers, and HSP70. The current study managed to show that while intermittent fasting of Ramadan in Turkey significantly reduces the TNF-alpha and IL-6 levels, while IL-8 levels remain unchanged. Since those are the main proinflammatory cytokines, there are studies in the literature in which proinflammatory cytokines are measured during fasting and Ramadan fasting specifically (Faris et al., 2012). Ramadan fasting dropped both TNF-alpha and IL-6 levels significantly almost to one third of the initial levels. Not only in humans but in mammalians such as rat, researchers showed that fasting may reduce TNF-alpha and IL-6 levels to the half of the initial levels (Speaker et al., 2016). The results of our study was consistent with the literature and we found that Ramadan fasting reduced TNF-alpha and IL-6 levels significantly which means intermittent fasting of Ramadan may be beneficial for reducing inflammatory response and limit the damage caused by over-reacting of human body via inflammatory elements. Interestingly it is not the same in all studies in the literature (Safavi \& Rahbar, 2017), also showed that post-Ramadan TNF-Alpha levels were lower and pre-Ramadan TNF-alpha levels. But the difference was not significant like in other studies in the literature including the present study. Although IL-8 is very important cytokine which is related many crucial biological functions including inflammation, there is very limited amount of information about the levels of IL-8 during the fasting. One came out recently, at the beginning of 2020 in which Almeneessier et al. (Almeneessier et al., 2019) investigated circadian levels of proinflammatory cytokines in Ramadan. They found that Ramadan fasting reduced the levels of IL-8, nonetheless difference was not significant and dramatically prominent in TNF-alpha and IL-1beta. These results are completely parallel to our study since we also find no difference in levels of IL-8.

Oxidative stress is also one of the critical biological condition which effects and takes part in almost any diseases. It is important to detect if intermittent fasting has any effect on oxidative status of human body. That is why we have measured TAS and TOS in Ramadan. Our results demonstrated while TOS levels were reduced after Ramadan fasting, TAS levels were stayed unchanged. The literature is quiet parallel to our study. In many studies in the literature, it has been shown that Ramadan fasting reduces TOS levels while increasing the total antioxidant capacity (Karsen et al., 2019) (Ozturk et al., 2011). The only difference is that TAS levels did not increased significantly in the current study. Nevertheless, there is a study conducted by Mohd Adzim Khalili et al. (Mohd Adzim Khalili et al., 2014) where TAS levels were similar before and after the Ramadan fasting similar to our study.

Finally, we also measured the levels of HSP70 before and after the Ramadan fasting. It has for some time been realized that if cells are presented to a sublethal worry before being presented to a deadly pressure, their opposition against the deadly pressure will be expanded because of the enlistment of warmth stun proteins (HSPs) by the sublethal stress. This wonder is viewed as pressure tolerance (Hartl et al., 2011) notwithstanding cells, tissues can likewise create pressure resilience when presented to a sublethal stress (Karimi et al., 2009).

As far as we know there is very limited amount of information about heat shock proteins and fasting especially Ramadan fasting. In a study very similar to ours in terms of design Zare et al. showed that HSP70 levels were increased after Ramadan fasting. This finding is identical with the present study (Zare et al., 2011). The HSP70 levels were significantly high at the end of the Ramadan when compared the initial levels of HSP70.

In conclusion, the ideas about fasting is changing in the last years with the detailed studies about different fasting method. Intermittent fasting which is typical for Ramadan fasting is studied extensively. Ramadan fasting seems to have anti-inflammatory, antioxidant effects and protective against cellular stress. Although there results need to be verified by detailed proteomic and metabolomic studies, well executed Ramadan diet may be beneficial for human health in many ways.

\section{References}

Aksungar, F. B., Eren, A., Ure, S., Teskin, O., \& Ates, G. (2005). Effects of intermittent fasting on serum lipid levels, coagulation status and plasma homocysteine levels. Annals of Nutrition and Metabolism. https://doi.org/10.1159/000084739

Almeneessier, A. S., BaHammam, A. A., Alzoghaibi, M., Olaish, A. H., Nashwan, S. Z., \& BaHammam, A. S. (2019). The effects of diurnal intermittent fasting on proinflammatory cytokine levels while controlling for sleep/wake pattern, meal composition and energy expenditure. PLoS ONE. https://doi.org/10.1371/journal.pone.0226034 
Almeneessier, A. S., \& Bahammam, A. S. (2018). How does diurnal intermittent fasting impact sleep, daytime sleepiness, and markers of the biological clock? Current insights. In Nature and Science of Sleep. https://doi.org/10.2147/NSS.S165637

Birben, E., Sahiner, U. M., Sackesen, C., Erzurum, S., \& Kalayci, O. (2012). Oxidative stress and antioxidant defense. In World Allergy Organization Journal. https://doi.org/10.1097/WOX.0b013e3182439613

Daugaard, M., Rohde, M., \& Jäättelä, M. (2007). The heat shock protein 70 family: Highly homologous proteins with overlapping and distinct functions. In FEBS Letters. https://doi.org/10.1016/j.febslet.2007.05.039

Erel, O. (2003). A novel automated direct measurement method for total antioxidant capacity using a new generation, more stable ABTS radical cation. Clinical Biochemistry. https://doi.org/10.1016/j.clinbiochem.2003.11.1015

Erel, Ozcan. (2005). A new automated colorimetric method for measuring total oxidant status. Clinical Biochemistry. https://doi.org/10.1016/j.clinbiochem.2005.08.008

Faris, M. A. I. E., Jahrami, H. A., Obaideen, A. A., \& Madkour, M. I. (2019). Impact of diurnal intermittent fasting during Ramadan on inflammatory and oxidative stress markers in healthy people: Systematic review and meta-analysis. In Journal of Nutrition and Intermediary Metabolism. https://doi.org/10.1016/j.jnim.2018.11.005

Faris, M. A. I. E., Kacimi, S., Al-Kurd, R. A., Fararjeh, M. A., Bustanji, Y. K., Mohammad, M. K., \& Salem, M. L. (2012). Intermittent fasting during Ramadan attenuates proinflammatory cytokines and immune cells in healthy subjects. Nutrition Research. https://doi.org/10.1016/j.nutres.2012.06.021

Fedail, S. S., Murphy, D., Salih, S. Y., Bolton, C. H., \& Harvey, R. F. (1982). Changes in certain blood constituents during Ramadan. American Journal of Clinical Nutrition. https://doi.org/10.1093/ajcn/36.2.350

Gilmore, T. E. (2001). Book Review: Clinician's Complete Reference to Complementary \& Alternative Medicine. American Journal of Hospice and Palliative Medicine ${ }^{\circledR}$. https://doi.org/10.1177/104990910101800316

González, O., Tobia, C., Ebersole, J. L., \& Novak, M. J. (2012). Caloric restriction and chronic inflammatory diseases. In Oral Diseases. https://doi.org/10.1111/j.1601-0825.2011.01830.x

Hallak, M. H., \& Nomani, M. Z. A. (1988). Body weight loss and changes in blood lipid levels in normal men on hypocaloric diets during Ramadan fasting. American Journal of Clinical Nutrition. https://doi.org/10.1093/ajcn/48.5.1197

Hartl, F. U., Bracher, A., \& Hayer-Hartl, M. (2011). Molecular chaperones in protein folding and proteostasis. In Nature. https://doi.org/10.1038/nature10317

Ibrahim, W. H., Habib, H. M., Jarrar, A. H., \& Al Baz, S. A. (2009). Effect of Ramadan fasting on markers of oxidative stress and serum biochemical markers of cellular damage in healthy subjects. Annals of Nutrition and Metabolism. https://doi.org/10.1159/000172979

Karimi, N., Hassan, Z. M., Rasuli, M. B., Ilkhanizadeh, B., Salarilak, S., \& Shahabi, S. (2009). The role of endogenous opioids in the protective effects of local sublethal hyperthermia against the progression of burn injury. Journal of Thermal Biology. https://doi.org/10.1016/j.jtherbio.2009.03.007 
Karsen, H., Güler, E. A., Binici, İ., Taşkıran, H., Yıldırım, S., \& Koyuncu, İ. (2019). Oxidant and antioxidant parameters in people who fast during Ramadan, and those who do not. African Health Sciences, 19(3), 2713-2717. https://doi.org/10.4314/ahs.v19i3.46

Mindikoglu, A. L., Opekun, A. R., Gagan, S. K., \& Devaraj, S. (2017). Impact of Time-Restricted Feeding and Dawn-to-Sunset Fasting on Circadian Rhythm, Obesity, Metabolic Syndrome, and Nonalcoholic Fatty Liver Disease. In Gastroenterology Research and Practice. https://doi.org/10.1155/2017/3932491

Mohd Adzim Khalili, R., M.Z, Z. H., Norhayati, A. ., Mohd Nasir, M. ., Muralidara, D. ., \& Intan Suhana Munira, M. . (2014). Study on ramadan fasting towards lipid profiles and total antioxidant status (TAS) among higher institution learning centre staffs. World Journal of Pharmaceutical Research, September.

Murphy, M. E. (2013). The HSP70 family and cancer. Carcinogenesis. https://doi.org/10.1093/carcin/bgt111

Ozturk, E., Balat, O., Ugur, M. G., Yazícíoglu, C., Pence, S., Erel, Ö., \& Kul, S. (2011). Effect of Ramadan fasting on maternal oxidative stress during the second trimester: A preliminary study. Journal of Obstetrics and Gynaecology Research, 37(7), 729-733. https://doi.org/10.1111/j.14470756.2010.01419.x

Roky, R., Chapotot, F., Hakkou, F., Benchekroun, M. T., \& Buguet, A. (2001). Sleep during Ramadan intermittent fasting. Journal of Sleep Research. https://doi.org/10.1046/j.13652869.2001.00269.x

Safavi, E., \& Rahbar, A. R. (2017). Effect of Intermittent Fasting during Ramadan on Visfatin , Adiponectin and Tumor Necrotizing Factor- Alpha in Healthy Muslim Individuals. https://doi.org/10.22038/jfh.2017.22719.1084

Shankar, K., \& Mehendale, H. M. (2014). Heat-Shock Proteins. In Encyclopedia of Toxicology: Third Edition. https://doi.org/10.1016/B978-0-12-386454-3.00320-1

Sinha, N., \& Dabla, P. (2015). Oxidative Stress and Antioxidants in Hypertension-A Current Review. Current Hypertension Reviews. https://doi.org/10.2174/1573402111666150529130922

Speaker, K. J., Paton, M. M., Cox, S. S., \& Fleshner, M. (2016). A Single Bout of Fasting (24 h) Reduces Basal Cytokine Expression and Minimally Impacts the Sterile Inflammatory Response in the White Adipose Tissue of Normal Weight F344 Rats. Mediators of Inflammation. https://doi.org/10.1155/2016/1698071

Yu, S. L., Kuan, W. P., Wong, C. K., Li, E. K., \& Tam, L. S. (2012). Immunopathological roles of cytokines, chemokines, signaling molecules, and pattern-recognition receptors in systemic lupus erythematosus. In Clinical and Developmental Immunology. https://doi.org/10.1155/2012/715190

Zare, A., Hajhashemi, M., Hassan, Z. M., Zarrin, S., Pourpak, Z., Moin, M., Salarilak, S., Masudi, S., $\&$ Shahabi, S. (2011). Effect of Ramadan fasting on serum heat shock protein 70 and serum lipid profile. Singapore Medical Journal. 